\title{
Health protection and promotion at work*
}

\author{
R S F SCHILLING
}

From the London School of Hygiene and Tropical Medicine, London WCIE 7HT, UK

ABSTRACT Official United Kingdom figures record annually 1400 deaths and 145000 sufferers from chronic effects of occupational injury and disease. Evidence indicates that occupational disease directly due to work is underestimated. With more understanding of the multiple causes of disease, the concept of work related disorders has broadened to include four categories: work as a direct cause, a contributory cause, or an aggravating factor, and work offering easy access to potential dangers (alcohol). As an example, work factors that increase the risk of coronary heart disease are discussed. Evidence for work stress as a causal factor and the role of leadership are considered. Prevention depends on identifying risks, preferably before anyone is exposed, but more commonly through recognition of adverse effects on workers. The need for occupational health services to have health promotion programmes that include screening for disease and its precursors, counselling and education, is considered. The positive effects of work itself as a protector and promoter of health are discussed. Responsibility for improving health has to be shared by government, management, trade unions, health professionals, and the individual worker.

Opportunities in workplaces for improving health include protection against injury and disease and health promotion. Work itself can also be a protector and promoter of health. Protecting workpeople from injury and disease is required by law and is accepted as an essential function of an occupational health service. Less than half the British workforce has access to these services, ${ }^{1}$ many of which are restricted because their staff are not professionally trained to practise occupational health.

Health promotion is given special emphasis in a recent government white paper $^{2}$ but there is no mention of occupational health services contributing. Not all employers or doctors would agree that health promotion in the sense of changing people's life styles is a function of a worksite health service. I quote an employer in a major industry: the policy of this company and its medical department is to concentrate on health issues directly related to work on the basis that it is the responsibility of national agencies and the National Health Service to address the more general problems.'

Work as a protector and promoter of health is a more controversial issue. Although many think of it as *Based on the Bayliss Lecture delivered at the Royal Society of
Medicine, London, on 5 December 1988.

Accepted 3 April 1989 having a negative influence on health, much of the stress engendered by a distasteful or hazardous occupation can be prevented by eliminating or controlling adverse environmental factors. Work can have a positive effect on the health of people in their old age who are said to be kept alive by work or hobbies stretching body and mind. For the severely disabled work, not necessarily paid work, can dramatically improve their quality of life and well being. Promoting better health depends on measures to change life styles, to prevent disease, and to treat illness. It is necessary to have the type of society that offers a useful and rewarding role for the disabled and the aged. ${ }^{3}$

\section{Health protection}

Work related injury and disease, caused by known adverse environmental agents, offer considerable scope for prevention. Once identified they have to be controlled; too often they are regarded as an inevitable consequence of work. Work place hazards are many and varied (table 1).

\section{INCIDENCE OF WORK RELATED INJURY AND DISEASE}

According to official records, the number of people killed, injured, or made sick by the above agents is relatively small. Some 1400 deaths a year are reported as directly due to work ${ }^{4} ; 650$ from accidents and 750 
Table 1 Categories of adverse environmental agents

\begin{tabular}{ll}
\hline Category & Examples \\
\hline Physical & Cold \& radiation \\
Chemical & Metal compounds, solvents \\
Biological & Tuberculosis, viral hepatitis \\
Ergonomic & Poor work design \\
Psychosocial & Bad management \\
Dangerous work practices & Unguarded machinery \\
\hline
\end{tabular}

from occupational diseases prescribed under the Industrial Injuries Act. This is an annual incidence of 50 per million in the British workforce, a tiny figure compared with an annual death rate for all ages of 3940 per million for heart disease. Some 145000 people suffer from the chronic effects of recognised work related injury and disease; a figure virtually unchanged from year to year. ${ }^{5}$ Do these figures give a true picture of the toll of work related injury and disease? Usually a work injury can be linked with a particular event and easily identified. Occupational disease is more difficult to identify. There may be a long delay between exposure to a harmful agent and the effect it causes. For example, occupational cancers can take many years to develop. Occupational causes of disease are easily missed if the doctor fails to inquire about the patient's job.

Psychiatrists, for example, need to know of the commonly used chemicals which can cause behavioural disorders. A university lecturer who was being treated for anxiety and depression attended a course on health and safety in the laboratory. The lecture on metal poisons made him think that exposure to mercury might have caused his condition. Investigation of his laboratory found pools of mercury under the floorboards, with airborne concentrations of mercury vapour above the exposure limits set by the Health and Safety Executive.

The official figures for occupational disease are based on the prescribed diseases for which social security pays compensation. The conditions for prescription are rigorous and many work related disorders are omitted.

Finland has an occupational disease register and an occupational health service, supported by an Institute of Occupational Health, which are the envy of other European counties. Finland has about 1200 fewer cases a year of occupational disease than the United Kingdom (table 2). Taking account of their smaller working population (a tenth of ours) Finland records nearly ten times more occupational disease than Britain. This reflects, without much doubt, more effective recording in Finland, not better British work practices.

MULTIPLE CAUSES OF DISEASE AND INJURY So far only those injuries and diseases directly caused by hazards in the workplace have been consideret. This was the scope of occupational medicine in the 1930s when I became an assistant physician in factory in the Midlands. The distinction between occupational and non-occupational disease w零 encouraged in order to define and limit areas of responsibility and to preserve the status of occupational medicine as a separate specialty. A bette understanding of the multiple causes of disease an more advanced techniques for identifying risk factors in common disorders such as coronary heart disease (CHD) has broadened the concept of occupationat health. In a working population disease can be thought of as the product of many interacting causess These may be grouped as host factors inherent in the worker, such as atopy, factors in the work enviro ment, and individual behaviour-for example, smoking and attitudes to personal safety. ${ }^{7}$ Thus it is possibje to visualise four categories of work related disorde $\overrightarrow{\mathbb{S}}$ (table 3).

The identification of diseases and injuries categories 1 and 3 is relatively straightforwa provided that the patient's occupation is borne in mind. The course and severity of a non-occupationg disease may be influenced in various ways. Psorias may worsen when there is work stress or in areas of skin irritated by mechanical, chemical, or physical agents (Koebner's phenomenon). Exposure to inees dusts may trigger asthmatic attacks in people ofith hyperreactive airways. In some conditions suct chronic bronchitis and peptic ulcer it is difficu distinguish between work acting as a causs provocative, or aggravating agent. If the adverse wo effect has been identified this distinction is relevant common law compensation but not to patient care. Category 4, work related disease, may be observed ing individuals or identified by studies of occupationaj groups. The classic example is liver cirrhosis innkeepers and bar tenders. A high risk of suicide medical laboratory workers is a more recent finding ${ }^{8}$ Preventing these catastrophies is difficult and sometimes impossible. Limiting access to the harmf agent with counselling and support programmes mày be helpful. Category 2, work related disease, includess conditions such as $\mathrm{CHD}$, hypertension, mental illness, and low back pain.'

Table 2 Recorded cases of occupational disease during $12 \mathrm{~N}$ months in 1986-7

\begin{tabular}{|c|c|}
\hline $\begin{array}{l}\text { Finland } \\
\text { United Kingdom }\end{array}$ & $\begin{array}{l}6204^{*} \\
7400 \dagger\end{array}$ \\
\hline
\end{tabular}

*Figures by courtesy of Professor Rantanen, Finland. †Estimated from DHSS prescribed disease awards and RIDDQB notifications of industrial disease. ${ }^{6}$ 
Table 3 Categories of work related disease and injury

\begin{tabular}{ll}
\hline Category & Examples \\
\hline 1 Work the direct cause & Lead poisoning, injury \\
2 Work a contributory cause & Coronary heart disease \\
3 Work an aggravating factor & Psoriasis, peptic ulcer \\
4 Work with easy access & Innkeeping: cirrhosis, \\
to potential dangers & Laboratory: suicide \\
\hline
\end{tabular}

\section{CORONARY HEART DISEASE AND WORK}

Risk factors, associated with life style, predispose people to CHD. They include smoking, diet, and lack of exercise which is not just a lifestyle issue. Since the classic observation that conductors on double decker buses have less CHD than drivers, ${ }^{10}$ evidence has accumulated that a sedentary work life increases the risk of high blood pressure and heart attack.

Exposure to certain toxic agents at work, such as carbon disulphide, gun cotton, solvents, and carbon monoxide may also increase the risk." This type of work related disease can only be identified by the study of its distribution and determinants in populations. Epidemiology, for example, showed that viscose rayon workers exposed to carbon disulphide (CS2) had a significant mortality excess from CHD. ${ }^{12}{ }^{13}$ In a factory in Finland levels of CS2 in the plant were reduced by a factor of 4 and workers with any evidence of CHD were moved to jobs with no exposure to CS2. The excess of deaths from CHD disappeared. It is estimated that this preventive action saved about 40 lives. ${ }^{14}$

\section{STRESS}

In a survey of some 40 large organisations representing employers and unions stress at work was given high priority as a cause of ill health. ${ }^{1}$ One of the reasons for this concern was the perceived link between stress and CHD. There is considerable debate about the causal connection between stress and CHD.$^{15}$ It is argued that most, if not all, the excess risk may be accounted for by the life style of stressed people-alcohol abuse, smoking, overeating, and being too sedentary. It is not possible to say with any certainty that stress has been a causal factor of CHD in an individual patient. Looking at groups of workers may be more helpful. At work the main causes of stress imposed on the individual by the organisation are said to be due to (1) the loadthat is, the burden of demands being too great or too small; (2) ambiguity, unclear direction; and (3) incompatible demands. ${ }^{16}$ Such factors which lead to stress are more amenable to measurement than stress itself. A study in the United States of a group of female clerks, monitored for CHD over 10 years showed the combined effects of highly demanding work and lack of clarity from their supervisors as a powerful predictor of CHD. CHD rates rose from $2 \cdot 4 \%$ in the low demand/high clarity group to $31.3 \%$ in the high demand/low clarity group (SG Haynes, Monterey, California, 1985). These associations persist after allowance is made for coronary risk factors of age, blood pressure, blood cholesterol, and cigarette smoking. Other studies in highly industrialised countries indicate that adverse psychosocial factors such as inability to use and develop skills, lack of authority over decisions, and poor social support are risk factors for cardiovascular illness. ${ }^{17}$ It helps to explain the higher mortality from CHD of workpeople in the lower social classes who are exposed to these psychosocial stressors.

It is commonplace to view stress as a failure of the individual to cope with work demands or life outside the workplace and to give help through relaxation, counselling, and anxiolytics, which is treating symptoms and not the cause. The real cause may lie in the way the organisation is managed, its leadership style, degree of worker participation, and level of fulfilment. My own experience suggests that good leadership is an effective antidote to adverse psychosocial factors that cause stress. I have seen examples of good and bad leadership in a variety of workplaces in industry, commerce, and academia.

I witnessed a high quality of leadership in an old steam trawler. The ship, although old, had avoided the scrapyard because of her excellent record. The skipper had attracted a good crew which stayed with him and there had been no serious casualties either to his men or his vessel. For a man in charge of a sea-going vessel, he had an unexpected humility. John Hunt, the Everest climber, includes humility among the qualities of a good leader. In 1955 in the Commemoration Oration at King's College, London, he said "Humility is proof of integrity; it is difficult to retain but only if it is retained will a leader be willing to seek and take advice from others ... to hear frank opinions and thus add to his wisdom. How many mistakes have been made by leaders who have lost contact with the thoughts of their subordinates."

Good leadership, I believe, stems from two qualities - namely, professional competence combined with a sense of caring for others and for their health and safety which is given the same priority as profit making and the public image of the organisation. Cutting corners on safety was a major factor in the underground railway disaster at King's Cross. ${ }^{18}$

\section{IDENTIFICATION AND PREVENTION OF RISKS}

Risks have to be identified and preferably predicted and dealt with before anyone is exposed. Toxicity testing is required for new substances. Agents known to be toxic, such as carcinogens, can be prohibited; others that are less toxic can be controlled at the design stage. More commonly, risks come to light through 
adverse effects on workpeople. Data on deaths and sickness, routinely collected by government departments and pension and funeral benefit schemes can help to identify risks. Not designed for this purpose, they have shortcomings. Special health information systems - for example, RIDDOR ${ }^{19}$ and registers for occupational diseases and cancer ${ }^{20}$ - have been set up by government departments and other organisations to obtain more reliable facts about adverse work effects. Nevertheless, routinely collected data, on their own, are no guarantee of finding the right answer. There is no substitute for going to the workplace to observe workers. The London School of Hygiene was asked to investigate Dogger Bank itch, an acute and debilitating skin disease affecting Lowestoft trawlermen. ${ }^{21}$ While at sea on a trawler, deck hands told me that we should be studying accidents among trawlermen. Their death rate was known to be high; the official figure, published by the Registrar General, was three times the rate of all men and below that of coalmining and other dangerous trades. ${ }^{22}$ Further investigation showed that deaths at sea were recorded separately by the Registrar General for shipping and seamen. Taking deaths at sea into account, the true risk of fishermen's fatal accidents was found to be 17 times greater than that of all men. Early in 1968 this excessive risk was brought home to the public by the loss of three trawlers and 58 men within a few weeks and was followed by an inquiry into trawler safety. ${ }^{23}$

On several occasions, by going to the worksite and talking to workpeople, I have been put on the right track or taken off the wrong one..$^{24}$ The first field survey we made of cotton workers was to examine them for hypertension because the Registrar General's data showed an apparent decline in respiratory deaths and an increase in cardiovascular and renal deaths among the men most exposed to dust. We found little of interest in their blood pressures but many of them had byssinosis which for some was disabling and at that time had been thought to be under control. On a trawler on another occasion I observed that deck hands looked old and tired after days of continuous fishing. Perhaps they were aging prematurely under their severe working conditions. I asked one who looked at least 70 how old he was. He replied 56 . When I told him that that was my age, he was staggered and remarked "I thought you were ten years older than me." So ended my theories about early senility among trawlermen.

Successful prevention depends on identifying hazards and then eliminating or controlling their causes. Health surveillance is an additional control measure undertaken by the physician or nurse. It can identify the vulnerable worker, encourage safer working, and indicate where environmental control is inadequate. Health surveillance is essential for people such as airline pilots, drivers, and food handlers whose disability may adversely influence the health anch safety of fellow workers and the public.

\section{Promoting health}

The government has outlined plans to encourage family doctors and primary health care teams to contribute to the promotion of good health. Occupational health services are excluded presumabl\% because, except in hospitals, they are not part of the National Health Service. Many occupational health services in larger organisations in the United Kingdom and other countries have health promotion pros grammes which include:

(1) screening for blood pressure, serum cholestero obesity, life style factors, and breast and cervicah cancer in women.

(2) counselling and education on smoking, diet $\overrightarrow{0}$ alcohol, and exercise. ${ }^{25}$

There are cogent reasons for health promotion programmes in workplaces. Occupational healty services have ready access to people before they get sick. Economic benefits to the employer should follow the reduction of unnecessary disability and the promog tion of better health. What is needed is good evidence of the effectiveness of coordinated health promotion programmes in British workplaces. ${ }^{3}$

Worksite health promotion has become American phenomenon for cultural and economie reasons. Participation in fitness and wellness is boon ing and is now an important part of their culture wit millions dedicated to jogging and other pursuitso American business and industry pay an estimated $30 \%$ of the national health bill by providing medicat insurance as an employee benefit. ${ }^{26}$ Worksite wellnes\$ programmes aim to keep employees healthy and te reduce health care costs and disability claims. A few. studies have shown that interventions lead to reduco tions in risk factors such as serum cholesterol, bloo $\$$ pressure, and smoking. It is too early to measure actual impact on disease. ${ }^{27}$ There are compelling dat 2 . from the studies of cost benefits, such as a saving to cost ratio of $1: 45$. Only rarely have interventions i⿺ such programmes included alterations in work organo isation, such as stressful management styles, the content of boring work, and noise abatement.

The worksite is the best place for taking action to prevent work related injury and disease. It is also an appropriate setting for a broader approach to promory tion and prevention. The aim of occupational health as defined by the World Health Organisation, is to promote health and the well being of workers in atf occupations. ${ }^{28}$ Successful prevention, like good treate ment, needs resources to encourage people througl personal contact and educational programmes to take 
Health protection and promotion at work

a more positive approach to health and safety, including change of life styles.

\section{Work itself as a protector and promoter of health}

For some people work offers opportunities for creative and stimulating activity. For the many who have dull, uninspiring jobs, it provides a base for establishing social contacts and companionship. Conversely, there is strong evidence that unemployment is damaging to health. ${ }^{1529}$ Furthermore, I quote from Stephen Taylor's Natural History of Everyday Life. "Without work life would cease to exist. For the individual, work seems to be essential for both physical and mental health, though one must add the rider that fully occupied leisure counts for this purpose as work."

As a nation we face a major social problem with six million disabled people, two thirds of whom are aged 65 or more. ${ }^{31}$ Many of them have a low quality of life because they are poor, unable to work, and not able to do things for themselves. While relief of poverty has first priority, as much as possible should be done to help the handicapped to be more independent, to pursue hobbies and other interests, and even to work gainfully. They can be helped by special equipment which gives them control over their home environment and the ability to communicate where there is difficulty in speaking and writing. An electronic appliance, supplied by Possum Controls Ltd, ${ }^{*}$ has enabled a man, severely disabled by multiple sclerosis, to run an accountancy business and a charity which helps others similarly handicapped. ${ }^{32}$ In the United Kingdom more than 2000 severely disabled people (less than $6 \%$ of whom are over 65) use this type of equipment which is supplied free of charge by government health departments as well as being fully maintained and serviced. Few are gainfully employed but many are active in other ways and are self reliant. Many of the 250000 severely disabled ${ }^{31}$ could be helped in this way if more doctors, nurses, social workers, and occupational therapists were aware of the availability of this type of help.

Women's superior longevity over men begins at retiring age and gradually increases. Nearly $88 \%$ of the over 100 age group in England and Wales are women. The causes underlying this sex difference are complex. Cyril Clarke, an eminent physician and geneticist, suggests one reason why women live longer. There is no retirement for them whereas many men, after gainful employment ceases, become less active both physically and mentally. ${ }^{33}$

*Further information available from Possum Controls Ltd, Middlegreen Road, Langley, Slough, Berkshire SL3 6DF. Tel 0753 79234: A charity owned company supplying equipment for the disabled.
The sex difference in life expectancy is similar for European and Asian countries. In Israel, however, the difference is less and may arise from the kibbutz pattern of active living which is similar for men and women. ${ }^{34}$

A challenging hypothesis is that postretirement activity affects survival, decreases inappropriate use of health services, and increases well being. A major difficulty in its testing is to overcome the healthy retiree effect-that is, healthy retirees will be more active than the less healthy. With many thousands of subscribers in the 60-64 age group, it should be possible for organisations, such as Private Patients Plan, to obtain an insight into the protective effects of work in old age by comparing the health and survival of active and inactive groups with similar preretirement claims records. The necessary information is available in existing records, except for postretirement activity and personal factors that influence survival.

\section{Whose responsibility?}

The government, employers, and employees have clear cut responsibilities for health and safety which follow the principle of self regulation introduced into the Health and Safety at Work Act of $1974 .^{35}$

The government sets and enforces standards of health and safety and should stipulate the services needed to achieve them. Present occupational health services in the United Kingdom reach a small proportion of the working population and some do not have the professionally trained staff to practise occupational health. Britain as a member state of the International Labour Organisation should ratify the ILO's convention and its recommendation which require services to be developed for all workers ... and staff trained in their specialty. ${ }^{36}$

Management should give a high priority to health and safety and the organisation of work to reduce stress.

Trade unions should be watch dogs for health and safety standards and participate in policy making and management of services.

Health professionals should advise management and individual workers on achieving and maintaining the highest possible standards of health and safety. They need to be properly funded and professionally trained.

\section{PERSONAL RESPONSIBILITY}

Fifty years ago, when I began my career in occupational medicine as a medical officer in a large factory, it was universally accepted that workpeople could not or would not take responsibility for their own health and safety. Control measures had to be provided by management and, so far as possible, made 
foolproof. This reflected a paternalism that is no longer acceptable in the western world. It has been superceded by co-partnership between management and the workforce. It applies not only to the prevention of work injury and disease but also to health promotion. Individual workers need to be fully informed and educated so that they can participate in raising the standards of health and safety in the workplace and in making decisions about changing their own life styles to improve health.

I thank Private Patients Plan for the invitation to give the second Bayliss Lecture and those who helped me in its preparation, particularly $\mathrm{Mr}$ Tony Webb and $\mathrm{Dr}$ Bobbie Jacobson, co-authors of Health at Work?, Dr Richard Rycroft, colleagues at the London School of Hygiene and Tropical Medicine, and members of my own family.

Requests for reprints to: RSFS, 11c Prior Bolton Street, London N1 2NX.

\section{References}

1 Webb T, Schilling R, Jacobson B, Babb P. Health at work? London: Health Education Authority, 1988. (Research report No 22.)

2 Promoting better health. London: HMSO, 1987. (Cmd 249.)

3 Smyth A, Jacobson R, eds. The nation's health: a strategy for the 1990s. London: King Edward's Hospital Fund, 1988.

4 Central Statistical Office. Annual abstract of statistics; industrial diseases and fatal injuries at work. London: HMSO, 1987.

5 Department of Health and Social Security. Statistics 1985. Section on industrial disablement benefit. London: HMSO, 1986.

6 Health and Safety Commission/Executive. Annual report 1986/87. London: HMSO, 1987.

7 Morris JN. Uses of epidemiology. 3rd ed. Edinburgh: Churchill Livingstone, 1975.

8 Harrington JM, Oakes D. Mortality study of British pathologists. Br J Ind Med 1984;41:188-91.

9 World Health Organisation. Identification and control of workrelated diseases. Geneva: WHO, 1985. (Tech rep series No 714.)

10 Morris JN, Heady A, Raffle PAB, Roberts CG, Parks JW. Coronary heart disease and physical activity at work. Lancet 1953;ii:1053-7.

11 Rosenham KD. Cardiovascular disease and environmental exposure. Br J Ind Med 1979;36:85-97.

12 Tiller JR, Schilling RSF, Morris JN. Occupational toxic factor in mortality from coronary heart disease. $\mathrm{Br}$ Med J 1968;iv: 407-11.

13 Sweetnam PM, Taylor SWC, Elwood PC. Exposure to carbon disulphide in a viscose rayon factory. $\mathrm{Br} J$ Ind $\mathrm{Med}$ 1987;44: 220-7.

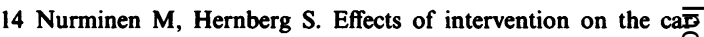
diovascular mortality of workers exposed to carbon disulphide. a 15 year follow up. Br J Ind Med 1985;42:32-5.

15 Bayliss R. Your health-whose responsibility? PPP Press Offico Tavistock House, Tavistock Sq, London WCl. (Bayliss lecture 1987.)

16 Egdell HG, Horrocks FA, Lee K, Warburton JW. Psychiatric disorders, alcohol and drug abuse. In: Edwards FG, McCallu RI, Taylor PJ, eds. Fitness for work. Oxford: Oxford Universi Press, 1988.

17 Marmot M, Theorell T. Social class and cardiovascular disease the contribution of work. International Journal of Heali Services 1988;18:659-74.

18 Fennell D. Investigation into the King's Cross underground fire. London: HMSO, 1988. (Cmd 499.)

19 Health and Safety Executive. $A$ guide to the reporting of injuries, diseases and dangerous occurrences (RIDDOR). London: HSE 1987.

20 Schilling RSF. Sources of data. In: Karvonen M, Mikheev MP eds. Epidemiology of occupational health. Copenhagen: Worlg Health Organisation, 1988. (Regional pubs, European series $\mathrm{NQ}$ 20.)

21 Newhouse ML. Dogger Bank itch: survey of trawlermen. Br Meḋ 1966;i:1142-5.

22 Schilling RSF. Hazards of deep-sea fishing. $\mathrm{Br} J$ Ind $M$ 1971;28:27-35.

23 Committee of inquiry into trawler safety. Final report. Londo요 HMSO, 1969. (Cmd 4114. Holland Martin, chairman.)

24 Schilling RSF. Humble pie; armchair bound. World Medicine 1975; Feb 12:33-4.

25 World Health Organisation. Health promotion for working popul|्गि tions. Geneva: WHO, 1988. (Tech rep series No 714.)

26 Conrad P. Worksite health promotion: the context. Soc Sci Med 1988;26:485-9.

27 Conrad P. Wellness in the work place: potentials and pitfaßs work-site health promotion. Millbank Quarterly 198 65 : 255-74.

28 World Health Organisation. Joint ILO/WHO Committe Occupational Health. Third report. Geneva: WHO, 1951. (¥ect rep series No 135.)

29 Platt S, Kreitman N. Trends in parasuicide and unemploymea among men in Edinburgh 1968-82. Br Med J 1984;289:1029-3 D

30 Taylor Lord of Harlow. A natural history of everyday life; biographical guide for would-be doctors of society. Londō British Medical Journal Publications, 1988.

31 Martin J, Meltzer H, Elliot D. The prevalence of disability among adults. London: HMSO, 1988. (Report No 1. OPCS, soci survey division.)

32 Schilling RSF, Millard P. Special equipment for the severe disabled. In: Gilmore A, Gilmore S, eds. A safer deat multidisciplinary aspects of terminal care. New York: Plenum Press, 1988.

33 Clarke C. Increased longevity in man. $J \boldsymbol{R}$ Coll Physician 1986:20:122-5.

34 Bayliss R, Clarke C, Whitfield AGW. Problems in comparative longevity. J R Coll Physicians 1987;21:134-9.

35 Dawson S, Willman P, Bamford M, Clinton A. Safety at work: the limits of self-regulation. Cambridge: Cambridge Universit Press, 1988.

36 International Labour Organisation. Convention 161 and recommendation 171 on occupational health services. Geneva: ILE 1985. 